\title{
Ultra-stretchable Silicon Solar Cells for Standalone Wearable and Foldable Electronics Application
}

\author{
Nazek El-Atab \\ mmh Labs, Computer, Elecctrical \\ and Mathematical Sciences and \\ Engineering Division \\ King Abdullah University of \\ Science and Technology \\ Thuwal, Saudi Arabia \\ nazek.elatab@kaust.edu.sa
}

\author{
Nadeem Qaiser \\ mmh Labs, Computer, Elecctrical \\ and Mathematical Sciences and \\ Engineering Division \\ King Abdullah University of \\ Science and Technology \\ Thuwal, Saudi Arabia \\ nadeem.qaiser@kaust.edu.sa
}

\author{
Rabab Bahabry \\ Department of Physics, \\ University of Jeddah, Jeddah, \\ 21589-80200, Saudi Arabia \\ rabab.bahabry@kaust.edu.sa
}

\author{
Muhammad Mustafa Hussain \\ mmh Labs, Computer, Elecctrical \\ and Mathematical Sciences and \\ Engineering Division \\ King Abdullah University of \\ Science and Technology \\ Thuwal, Saudi Arabia \\ Elecctrical Engineering and \\ Computer Science \\ University of California, Berkeley \\ California, USA \\ muhammad.hussain@kaust.edu.s \\ a \\ mmhussain@berkeley.edu
}

\begin{abstract}
In order to achieve standalone wearable and foldable electronics, the integration of high efficiency stretchable energy harvesting devices is essential. Here, we demonstrate the development of ultra-stretchable solar cells based on monocrystalline silicon with interdigitated back contacts and high efficiency $(19 \%)$. The stretchability of the photovoltaic devices is achieved by encapsulating the originally rigid solar cell with an elastomer followed by applying a deep-reactive ion etching based corrugation technique. Two different corrugation patterns are investigated: linear and triangular. The results show that, due to the ability of the triangular designs to relieve the generated strain, the cells can be stretched by up to twice their original size with no noticeable decline in the initial performance.
\end{abstract}

Keywords—silicon, corrugation, stretchable, flexible, PV.

\section{INTRODUCTION}

The global market of portable electronics has been growing over the past years with expanding demands on functionality and portability [1-9]. Specifically, wearable and foldable electronic devices which seek to enhance the human's quality of life have experienced rapid growth. To achieve portability of such devices, it is crucial to integrate high efficiency stretchable energy harvesting and energy storage devices. Nevertheless, previously demonstrated stretchable solar cells have been either very inefficient (organic based, efficiency < 8\%) [10-15] or high cost with complicated fabrication processes [16-18]. In fact, previously shown inorganic stretchable solar cells have been mainly based on III-V materials and require transfer-printing of the thin-film based cell onto a pre-strained and patterned elastomer.

In this work, an ultra-stretchable silicon based solar cell with $19 \%$ efficiency is developed via a corrugation approach applied on large scale rigid cells. The encapsulation of the solar cell with a bio-friendly elastomer and the subsequent corrugation process result in a stretchable cell with no need for transfer-printing. The results show that the corrugation pattern is critical in relieving the generated strain during the application of the tensile stress and thus in increasing the stretching capability of the cell [1922].

\section{FABRICATION}

Stretchability in rigid silicon solar cells is achieved using a combination of elastomer encapsulation and corrugation process. In fact, the backside of a large scale rigid solar cell based on monocrystalline silicon is first coated with an elastomer (Ecoflex) and cured at room temperature for 2 hours. It is worth to note that the rigid solar cells have an efficiency of $19 \%$ and are based on the interdigitated back contacts technology. The front side of the cell is then coated with a hard mask which was next patterned using $\mathrm{CO}_{2}$ laser ablation. The silicon areas are then completely etched using a deep reactive

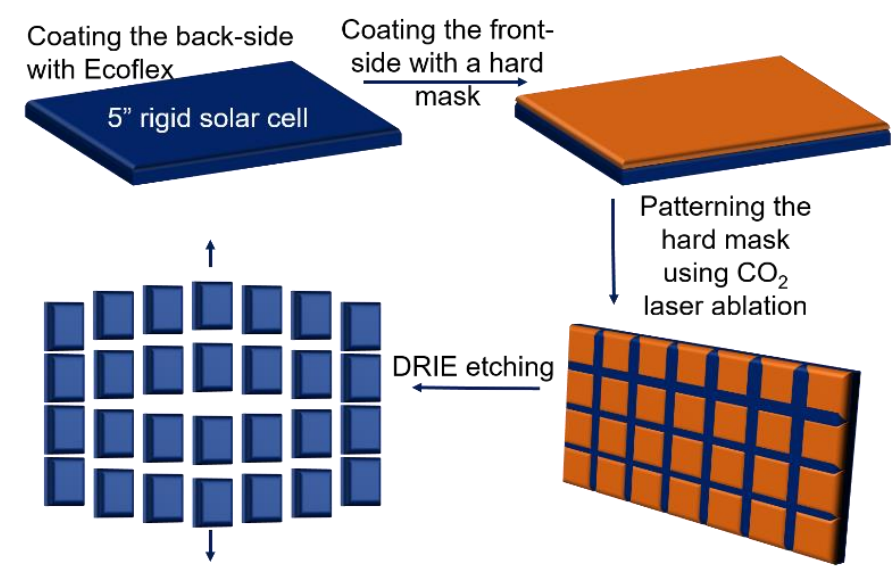

Fig. 1. Process flow of the corrugation approach for developing stretchable photovoltaic devices. 
ion etching (DRIE) system. As a result, ultra-stretchable solar cells are obtained. The fabrication process flow is illustrated in Fig. 1.

\section{RESULTS AND DISCUSSION}

Two different corrugation patterns are investigated: linear and triangular designs. In the case of the linear patterns, a spacing of $2 \mathrm{~mm}$ is used between the rectangular islands while a spacing of $1 \mathrm{~mm}$ is used in the case of the triangular patterns which leads to a reduced loss of silicon area as shown in Table I. Nevertheless, the additional diagonal patterns shown in the triangular patterns contribute to relieving the caused strain by the application of the tensile stress. This results in an extended stretchability of the cell. In fact, the linear patterned cell can be stretched up to $55 \%$ while the triangular can be stretched up to almost twice its original size (Table I).

The stretchable solar cells show ultra-flexibility as well as shown in Fig. 2 where a triangular patterned cell is depicted in its relaxed and stretched states. It is also worth to note that the solar cells can be stretched out asymmetrically as shown in Fig 2 (bottom) where a tensile stress is applied asymmetrically around the edges of the wafer-scale solar cell. This confirms the potential of the demonstrated solar cell in wearable electronic devices where asymmetrical stretchability is crucial.

The solar cells can also be stretched out in an out-of-plane manner as shown in Fig. 3 thanks to the design of the corrugated pattern where rectangular islands can shift and stretch perpendicularly to the plane of the solar cell. It is important to note that the initial performance of the solar cells is maintained after stretching the cells up 500 cycles ( $\eta$ of $19 \%$ and FF of around $75.8 \%$ as shown in Table II). This is due to the ability of the elastomer to completely absorb the generated strain while the rigid area remain intact. Moreover, the triangular stretchable solar cells show an ultralight weight of $0.67 \mathrm{~kg} / \mathrm{m}^{2}$ which is promising for portable electronics applications. It is also important to note that the linear corrugated cells with $17 \%$ loss of active area show a specific weight of $0.64 \mathrm{~kg} / \mathrm{m}^{2}$. Thus, depending on the application requirements, in terms of stretchability, mass and power yield, the corrugation pattern can be optimized accordingly.

TABLE I

STRETCHABILITY OF SOLAR CELLS

\begin{tabular}{|c|c|c|}
\hline & Linear & Triangular \\
\hline $\begin{array}{c}\text { Loss of active } \\
\text { area }\end{array}$ & $17 \%$ & $13.5 \%$ \\
\hline $\begin{array}{c}\text { Stretching } \\
\text { Capability }\end{array}$ & $55 \%$ & $95 \%$ \\
\hline
\end{tabular}
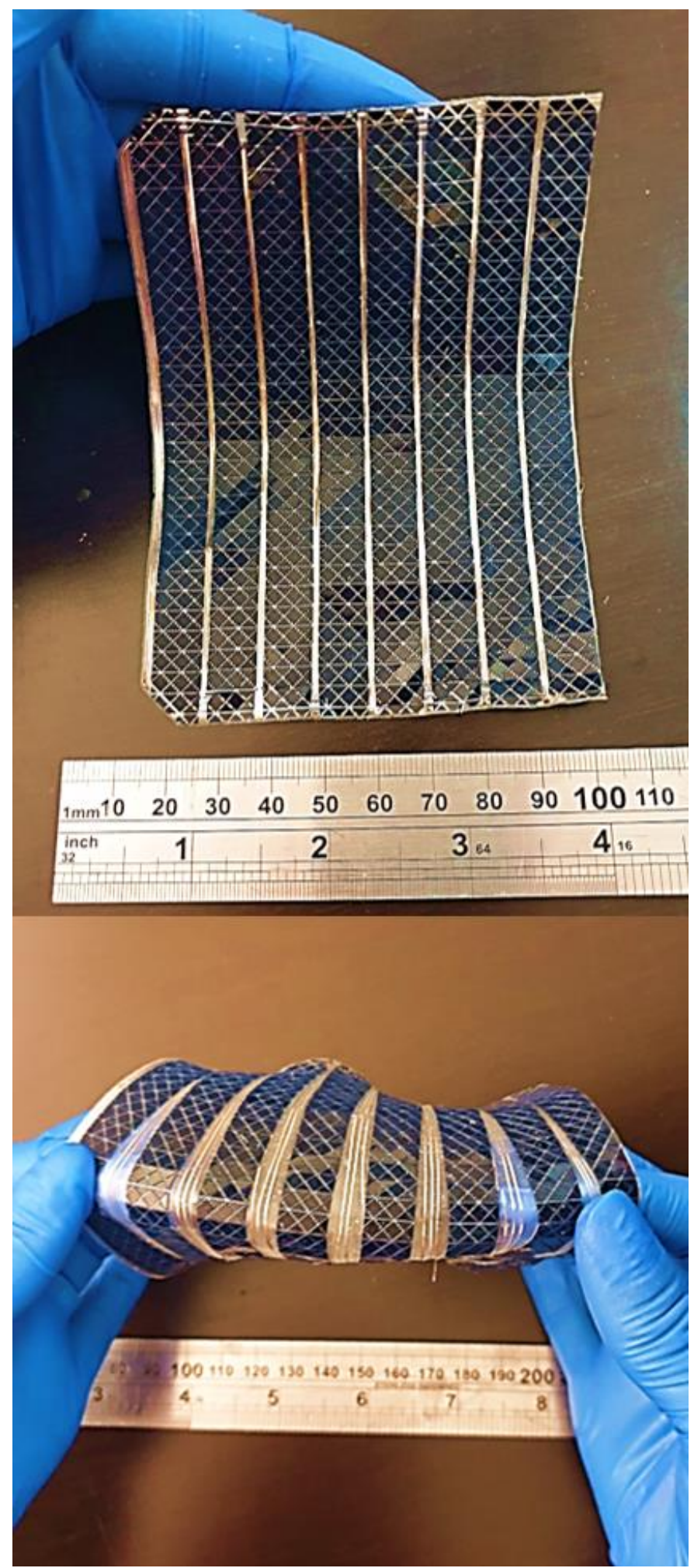

Fig. 2. Triangular shaped stretchable and flexible solar cells. The cells can be stretched by up to twice their original size. 


\section{TABLE II}

SUMMARY OF RIGID AND STRETCHABLE SOLAR CELLS CHARACTERISTICS

\begin{tabular}{|c|c|c|}
\hline & Rigid & Stretchable \\
\hline $\mathrm{J}_{\mathrm{sc}}$ & $39 \mathrm{~mA} / \mathrm{cm}^{2}$ & $38.8 \mathrm{~mA} / \mathrm{cm}^{2}$ \\
\hline $\mathrm{V}_{\mathrm{oc}}$ & $0.64 \mathrm{~V}$ & $0.64 \mathrm{~V}$ \\
\hline$\eta$ & $19 \%$ & $18.8 \%$ \\
\hline $\mathrm{FF}$ & $75.85 \%$ & $75.74 \%$ \\
\hline Specific weight & $0.78 \mathrm{~kg} / \mathrm{m}^{2}$ & $0.67 \mathrm{~kg} / \mathrm{m}^{2}$ \\
\hline
\end{tabular}

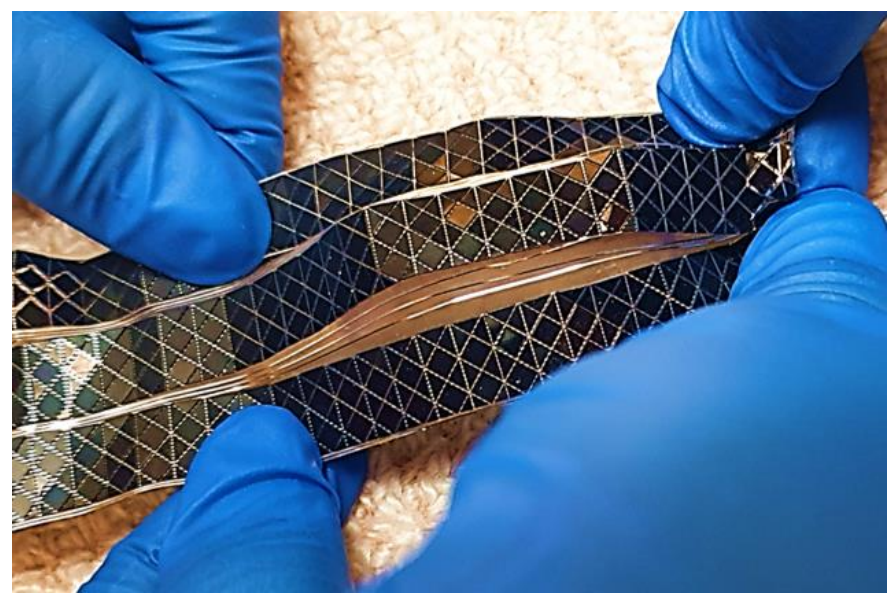

Fig. 3. Out-of-plane stretching capability of the corrugated solar cells.

\section{CONCLUSION}

In conclusion, ultra-stretchability in rigid solar cells is demonstrated using an elastomer encapsulation followed by the application of a corrugation technique. The corrugation process uses $\mathrm{CO}_{2}$ laser ablation followed by DRIE etching. Different corrugation patterns are investigated such as linear and triangular which result in various stretching capabilities but with a preserved efficiency of $19 \%$. In fact, the triangular solar cell is shown to relieve the generated strain during the tensile stress which enables a higher stretchability. However, the linear corrugated cell with a wider loss of silicon area enables a smaller overall mass. Therefore, the corrugation designs can be tailored to achieve the application requirements in terms of stretchability, specific weight and output power. Finally, the solar cells show the capability of stretching asymmetrically and out-of-plane which confirm their potential in wearable and foldable electronic devices.

\section{REFERENCES}

[1] N. El-Atab et al., "Heterogeneous Cubic Multidimensional Integrated Circuit for Water and Food Security in Fish Farming Ponds", Small, p. 1905399, 2019. Available: $10.1002 / \mathrm{smll} .201905399$.

[2] M. Mohammed and R. Kramer, "All-Printed Flexible and Stretchable Electronics", Advanced Materials, vol. 29, no. 19, p. 1604965, 2017. Available: 10.1002/adma.201604965.

[3] J. Ge et al., "Stretchable Electronics: A Stretchable Electronic Fabric Artificial Skin with Pressure-, Lateral Strain-, and Flexion-Sensitive Properties (Adv. Mater. 4/2016)", Advanced Materials, vol. 28, no. 4, pp. 783-783, 2016. Available: 10.1002/adma.201670027.
[4] Q. Hua et al., "Skin-inspired highly stretchable and conformable matrix networks for multifunctional sensing", Nature Communications, vol. 9, no. 1, 2018. Available: 10.1038/s41467-017-02685-9.

[5] D. Lipomi and Z. Bao, "Stretchable, elastic materials and devices for solar energy conversion", Energy \& Environmental Science, vol. 4, no. 9, p. 3314, 2011. Available: 10.1039/c1ee01881g.

[6] N. Zhang et al., "Biaxially stretchable supercapacitors based on the buckled hybrid fiber electrode array", Nanoscale, vol. 7, no. 29, pp. 12492-12497, 2015. Available: 10.1039/c5nr03027g.

[7] Y. Huang et al., "A self-healable and highly stretchable supercapacitor based on a dual crosslinked polyelectrolyte", Nature Communications, vol. 6, no. 1, 2015. Available: 10.1038/ncomms10310.

[8] S. Pang, Y. Gao and S. Choi, "Flexible and Stretchable Biobatteries: Monolithic Integration of Membrane-Free Microbial Fuel Cells in a Single Textile Layer", Advanced Energy Materials, vol. 8, no. 7, p. 1702261, 2017. Available: 10.1002/aenm.201702261.

[9] J. Rogers, T. Someya and Y. Huang, "Materials and Mechanics for Stretchable Electronics", Science, vol. 327, no. 5973, pp. 1603-1607, 2010. Available: 10.1126/science.1182383.

[10] D. Lipomi, B. Tee, M. Vosgueritchian and Z. Bao, "Stretchable Organic Solar Cells", Advanced Materials, vol. 23, no. 15, pp. 1771-1775, 2011. Available: 10.1002/adma.201004426.

[11] H. Jinno et al., "Stretchable and waterproof elastomer-coated organic photovoltaics for washable electronic textile applications", Nature Energy, vol. 2, no. 10, pp. 780-785, 2017. Available: 10.1038/s41560017-0001-3.

[12] Z. Yang, J. Deng, X. Sun, H. Li and H. Peng, "Stretchable, Wearable DyeSensitized Solar Cells", Advanced Materials, vol. 26, no. 17, pp. $2643-$ 2647, 2014. Available: 10.1002/adma.201400152.

[13] S. Yoon and D. Khang, "Stretchable, Bifacial Si-Organic Hybrid Solar Cells by Vertical Array of Si Micropillars Embedded into Elastomeric Substrates", ACS Applied Materials \& Interfaces, vol. 11, no. 3, pp. 32903298, 2018. Available: 10.1021/acsami.8b17826.

[14] Y. Zhang et al., "Buckling in serpentine microstructures and applications in elastomer-supported ultra-stretchable electronics with high areal coverage", Soft Matter, vol. 9, no. 33, p. 8062, 2013. Available: $10.1039 / \mathrm{c} 3 \mathrm{sm} 51360 \mathrm{~b}$.

[15] D. Son et al., "Multifunctional wearable devices for diagnosis and therapy of movement disorders", Nature Nanotechnology, vol. 9, no. 5, pp. 397404, 2014. Available: 10.1038/nnano.2014.38.

[16] D. Kim et al., "Stretchable and Foldable Silicon Integrated Circuits", Science, vol. 320 , no. 5875, pp. 507-511, 2008. Available: $10.1126 /$ science. 1154367.

[17] N. Bowden, S. Brittain, A. Evans, J. Hutchinson and G. Whitesides, "Spontaneous formation of ordered structures in thin films of metals supported on an elastomeric polymer", Nature, vol. 393, no. 6681, pp. 146-149, 1998. Available: 10.1038/30193.

[18] J. Lee et al., "Stretchable GaAs Photovoltaics with Designs That Enable High Areal Coverage", Advanced Materials, vol. 23, no. 8, pp. 986-991, 2011. Available: 10.1002/adma.201003961.

[19] N. El-Atab, N. Qaiser, R. Bahabry and M. Hussain, "Corrugation Enabled Asymmetrically Ultrastretchable (95\%) Monocrystalline Silicon Solar Cells with High Efficiency (19\%)", Advanced Energy Materials, vol. 9, no. 45, p. 1902883, 2019. Available: 10.1002/aenm.201902883.

[20] N. El-Atab, W. Babatain, R. Bahabry, R. Alshanbari, R. Shamsuddin and M. Hussain, "Ultraflexible Corrugated Monocrystalline Silicon Solar Cells with High Efficiency (19\%), Improved Thermal Performance, and Reliability Using Low-Cost Laser Patterning", ACS Applied Materials \& Interfaces, 2019. Available: 10.1021/acsami.9b15175.

[21] R.R. Bahabry, A.T. Kutbee, S.M. Khan, A.C. Sepulveda, I Wicaksono, M. Nour, N. Wehbe, A.S Almislem, M.T. Ghoneim, G.A. Torres Sevilla, A. Syed, S.F. Shaikh, M.M. Hussain. Advanced Energy Materials 8, $1702221,2018$.

[22] N. El-Atab, R. Shamsuddin, R. Bahabry, and M.M.Hussain "HighEfficiency Corrugated Monocrystalline Silicon Solar Cells with MultiDirectional Flexing Capabilities" $46^{\text {th }}$ IEEE PVSC, 1499-1501 
